\title{
Psychological Crisis in a Marathon and the Buffering Effects of Self-Verbalizations ${ }^{1}$
}

\author{
JULIA SCHÜLER ${ }^{2}$ \\ University of Zürich \\ Zürich, Switzerland
}

\author{
ThOMAS A. LANGENS \\ University of Wuppertal \\ Wuppertal, Germany
}

\begin{abstract}
In the present study, we investigated the effects of psychological crises on goal striving and the buffering effects of self-verbalizations in the context of a marathon race. Study 1 showed that during a marathon, a psychological crisis - which is characterized by a strong impulse of goal disengagement and thoughts about benefits and costs-occurred at about Kilometer 30 and that this crisis had negative effects on race performance. Study 2 experimentally induced the use of self-verbalizations. The results confirmed the hypothesis that self-verbalizations are an effective strategy to buffer against negative effects of psychological crisis on race performance. Selfverbalizations are discussed as a general self-regulatory tool in goal striving.
\end{abstract}

Goal striving has been a topic of great interest to early and modern researchers of motivation, as well as to practitioners (Burton, 1993; Heckhausen \& Gollwitzer, 1987; Kanfer \& Kanfer, 1991; Kuhl, 2000; Locke \& Latham, 1985; Tolman, 1932; Weinberg, 1994, 2002). Different focuses on goals have been used. Some researchers have focused on the characteristics of effective goals (e.g., Elliot \& Church, 1997; Emmons, 1989; Klinger, 1996; Locke \& Latham, 1990), whereas others have focused on the effects of goal striving, mostly on performance (for organizational contexts: Locke \& Latham, 1985; Locke, Shaw, Saari, \& Latham, 1981; for sports contexts: Burton, 1989; Burton, Naylor, \& Holliday, 2001; Weinberg, 1994).

Another perspective on goals is the process of goal striving itself. A well-known theoretical framework of the goal-striving process is the model of action phases (Gollwitzer, 1990; Heckhausen \& Gollwitzer, 1987). The model assumes that the course of goal striving consists of four phases. The first is the predecisional phase in which various wishes are deliberated according to their desirability and feasibility. It ends with forming a goal intention. The second phase is the preactional phase in which goal-related behavior must be initiated; for example, with the help of concrete action plans. The third phase is

${ }^{1}$ The authors thank Chantal Roth and Rosina Maag for their help with data collection.

${ }^{2}$ Correspondence concerning this article should be addressed to Julia Schüler, Department of Psychology, University of Zürich, Binzmühlestrasse 14/6, 8050 Zürich, Switzerland. E-mail: j.schueler@psychologie.unizh.ch 
the actional phase in which goal-relevant action takes place. In the postactional phase, goal attainment is evaluated. In the actional phase, barriers in goal striving (e.g., distractions, temptations) can lead goal-relevant actions off track and thus can endanger goal pursuit. Those barriers can be countered by self-regulatory strategies; for example, shielding the action from distractions (Kuhl, 1984). This is in accordance with Locke and Latham's (1990) assumption that goal striving is a comprehensive process in which barriers are a common phenomenon. One of their seven key steps in goal striving is evaluating the barriers to goal attainment. It is not enough (a) to set a goal and (b) to develop goal commitment, but one must also (c) anticipate and evaluate barriers that could hinder the goal-striving process. Then, (d) action plans must be constructed; (e) feedback must be obtained; (f) goal attainment must be evaluated; and, finally, (g) goal achievement must be reinforced.

According to Locke and Latham's (1990) seven steps, barriers are a natural part of most goal-striving processes. Whereas some barriers can be dealt with easily, others can seriously endanger goal attainment. Although such crises in goal striving seem to play an important role in the goal-striving process, there is little research that has analyzed this phenomenon and its antecedents and consequences in detail. An exception is Brandstätter (2003), who analyzed the psychological accompaniments of crises in goal striving among female members of a fitness center who intended to exercise regularly. Participants who experienced severe barriers in goal striving (action crisis, according to Brandstätter) reported more thoughts about costs of goal striving and benefits of goal disengagement than did participants without action crisis. Thinking about benefits and costs seems to be a cognitive indicator of a crisis that in Brandstätter's study was connected with lower goal commitment and lower persistence in goal-directed behavior. Taking these results as a starting point, we used thoughts about the costs of goal striving and the benefits of goal disengagement and, additionally, the impulse of disengagement as indicators of a psychological crisis in goal striving. We assume that psychological crisis influences goal attainment.

\section{The Marathon Race as Goal Striving}

A marathon has a great deal in common with other goals. As described by the model of action phases, the goal-striving process consists of setting a goal (e.g., "I want to cross the finish line"), striving for the goal (i.e., running), encountering barriers (e.g., exhaustion, frustration), overcoming barriers with self-regulatory strategies, and, in most cases, attaining the goal by crossing the finish line.

For some reasons, a marathon is an easy goal. It has a clearly defined starting point (i.e., the starting line) and a clearly defined criterion of goal 
attainment (i.e., the finish line). Furthermore, there are no doubts about actions that will lead to goal attainment: All a marathon runner must do is run. During goal striving, every kilometer is marked. Thus, regular feedback concerning the distance from the goal is provided. According to Kuhl (1983), an intention to act is promising in which the goal striver takes four elements into account: the state that he strives for, the actual state, the discrepancy between both states, and the action to minimize the discrepancy. For a marathon runner, all elements are given at every time.

In a marathon race, runners often encounter psychological and physiological barriers to successfully reaching their goal. The physiological functioning of a marathon runner is determined mostly by the availability of energy. At the start of a marathon race, energy is provided easily by glucose from muscles and the liver. But this source of energy is limited. Later in the race, energy must be gained from fat resources, which are not as readily available. A critical phase is the changeover from one main source of energy to the other. At about Kilometer 30, the source of glucose is diminished, while the energy requirement stays at a high level, and the transformation of fat resources does not yet operate efficiently. This is why an imbalance of energy requirement and energy availability can occur.

The extent of this energy crisis depends on many factors (e.g., intensity of prior training, food and water consumption during race) and varies among races and runners. Some marathon runners do not even notice it, whereas others experience it very strongly. In the colloquial language of marathon runners, a strong crisis is called the wall, because the experience feels like running into a wall. This wall is experienced as a severe barrier for running farther, and it feels hard to overcome. In order to differentiate psychological barriers from a physiological barrier (i.e., physical fatigue), we differentiate between psychological crisis of goal striving and physiological crisis of goal striving.

Although related, the experience of marathon runners suggests that psychological and physiological crises seem to be partly independent. Marathon runners often report a psychological crisis without any physiological symptoms or vice versa (also see Utter et al., 2002). A marathon runner can have a high impulse of goal disengagement because he is bored by doing the same thing (i.e., running) for hours; he may think about the costs of goal striving (e.g., spending a Sunday running instead of spending time with friends); or he may think about the benefits of goal disengagement (e.g., resting, relaxing).

It seems as if the impulse of disengagement and thoughts about the benefits of goal disengagement and the costs of goal striving can endanger the goal-striving process without the influence of any physiological processes. Thus, we assume that even if both types of crisis may depend on each other 
and thus explain a common part of variance of race performance, a psychological crisis accounts for variance that is independent of physiological crisis.

Another hint to support our assumption of a partial independence of both crises is that psychological and physiological processes are influenced differentially by psychological interventions. For example, Kanfer (1990) assumed that the effectiveness of different strategies depends on the type of barrier. Psychological strategies should work better for internal psychological barriers, whereas practical problem solving should work better for environmental barriers. In our research, we examine the idea of a barrier-depending effect of strategies. Therefore, we assume that psychological difficulties in goal striving could best be faced with psychological strategies such as self-regulatory strategies, whereas physiological crisis could best be overcome by physiological strategies such as resting, drinking, and eating to store energy. Thus, self-regulatory strategies should affect the consequences of psychological crisis in goal striving and should leave the consequences of physiological crisis unaffected.

\section{Self-Verbalizations as a Self-Regulatory Tool}

Although goal striving can be endangered by barriers such as distractions, temptations, and impulses of disengagement, people often continue to strive for their goals and eventually attain them. Self-regulatory strategies are effective tools to overcome barriers of goal pursuit (i.e., Carver \& Scheier, 1990). One example is the use of self-verbalizations. Self-verbalizations are speeches directed to the speaker himself (Vygotsky, 1934/1987). Adults use self-verbalizations to support problem solving when tasks are difficult and require special attention (Grote \& Baer, 2000; Hughes, 1992; for adult use of self-verbalizations, also see Duncan \& Cheyne, 1999; Kronk, 1994; Siegrist, 1995). Self-verbalizations also help to resist impulses of alternative behavior (Hartig \& Kanfer, 1973; Mischel \& Patterson, 1976). In the terms of goal researchers, self-verbalizations work by shielding off distractions from an ongoing goal-directed action (e.g., "Do not give up," "Just concentrate on the task").

Psychotherapists and sport psychologists especially use self-verbalizations as interventions in practical fields. For example, cognitive behavioral psychotherapists assist their patients to develop functional self-verbalizations to self-regulate thoughts, emotions, and behavior (Kanfer, Reinecker, \& Schmelzer, 2000; Meichenbaum, 1977a, 1977b; Meichenbaum \& Goodman, 1971). Self-verbalizations have proven to be particularly effective in the treatment of hyperactive children and stress-related disorders (Lauth \& Schlottke, 1997; Meichenbaum, 1977a). 
The effectiveness of self-verbalizations has also been demonstrated in sport psychology (e.g., Hardy, Hall, \& Alexander, 2001; Hardy, Hall, \& Hardy, 2004; Van Raalte, Cornelius, Brewer, \& Hatten, 2000). Here, selfverbalizations are interpreted as mental strategies that support selfmotivation and problem solving and that focus attention on task-related actions and distract from cues that may promote disengagement (Hardy et al., 2004, Schack, 1996; Ziemainz \& Stoll, 1999). As a consequence, selfverbalizations enhance athletic performance (e.g., Mahoney \& Avener, 1977; Whelan, Mahoney, \& Meyers, 1991). For example, female basketball players who used self-verbalizations reported fewer problems with concentration and anxiety than did a control group (Meyers, Schleser, \& Okwumabua, 1982).

Encouraged by empirical evidence of the effectiveness of selfverbalizations, we decided to test them in marathon runners. We assume that self-verbalizations are an effective self-regulatory tool that should help runners to maintain a high performance when they face barriers, such as psychological crisis. Assuming a barrier-depending effect of strategies, we suggest that self-verbalizations should affect psychological crisis, but leave physiological crisis unaffected.

\section{The Present Research}

The present research aims to assess indicators of psychological crisis over a marathon race, demonstrating its negative effects on race performance and testing whether self-verbalizations can buffer against the negative effects of psychological crisis on race performance. In order to identify a psychological crisis during a marathon race, we asked marathon runners to answer questions separately for four different periods of their race (at 10,20,30, and $40 \mathrm{~km}$ ). To test our first hypothesis (i.e., a psychological crisis exists during a marathon race), runners were asked to report about indicators of a psychological crisis (i.e., disengagement impulse, thoughts about the costs of goal striving, benefits of goal disengagement). We propose the following:

Hypothesis 1. Indicators of a psychological crisis will peak at $30 \mathrm{~km}$, thereby marking the point of strongest psychological crisis during a marathon race.

In addition, our research measures physiological crisis and performance in a marathon race (running time). We propose the following:

Hypothesis 2. Psychological crisis will be a significant negative predictor of race performance and will account for variance 
that is partially independent of the variance that can be explained by a physiological crisis.

To investigate whether self-verbalizations buffer against the negative effects of psychological crisis on race performance, we conducted an experiment in which one group of marathon runners was instructed to use individual self-verbalizations during the race, while another group of runners (i.e., control group) was not instructed to use self-verbalizations. If selfverbalizations are an effective self-regulatory tool, then the effects of psychological crisis on race performance should differ between groups.

Hypothesis 3a. Marathon runners who are experiencing a large psychological crisis and who use self-verbalizations will perform better than those who do not use self-verbalizations.

Hypothesis $3 b$. In the case of a small psychological crisis, no differences between groups are expected.

The use of self-verbalizations should leave physiological crisis unaffected.

To test our assumptions, we conducted two field studies. Study 1 is a correlational study that was conducted to test the existence of a psychological crisis and its negative effects on race performance. In Study 2, we used a control group in an attempt to replicate the results of Study 1. Study 2 tests a self-verbalization group against a control group without self-verbalizations.

\section{Study 1: Psychological Crisis and Its Consequences on Performance}

In order to identify a psychological crisis, we investigated the course of indicators of psychological crisis (i.e., impulse of disengagement, thoughts about the costs of goal striving and the benefits of goal disengagement). Indicators were measured at the beginning of the goal-striving process $(10 \mathrm{~km})$, at about the midpoint of goal striving $(20 \mathrm{~km})$, at a period that is expected to be physiologically difficult because of an energy imbalance $(30 \mathrm{~km})$, and at a period near the end of goal striving $(40 \mathrm{~km})$. We expect indicators of a psychological crisis to peak at about $30 \mathrm{~km}$ and expect them to be partly independent of a physiological crisis (as measured by physical symptoms). We hypothesize that psychological crisis is a significant negative predictor of race performance and accounts for variance over and above the effects of physiological crisis. 


\section{Method}

\section{Participants and Procedure}

Participants were recruited among non-professional marathon runners at a marathon exhibition in Cologne, Germany, 2 days prior to a race. A total of 129 runners ( 41 women, 88 men) who ranged in age from 18 to 62 years $(M=36.5$ years, $S D=7.55)$ agreed to participate in a study that was supposedly about motivation and feelings during a Marathon race.

Participants completed a first questionnaire directly on the exhibition ground. They were asked to report their age, gender, start number, training status, and the goals they set for the imminent marathon race. There were 12 participants who failed to write down a concrete time goal. They were excluded from analyses in which this variable was analyzed.

Participants were given a second questionnaire, which they were instructed to complete at home after the race. There were 9 participants who failed to send back the second questionnaire, as well as 11 participants who failed to write down their start numbers or wrote down a number that did not exist. Because the start number was needed to identify the dependent variable (see section entitled Race performance), the data of those participants had to be discarded. The number of valid data sets was 109 (including race performance, but not goal setting) and 97 for analyses in which the goal-setting variable was used.

\section{Measures}

Pre-race questionnaire. In order to control variables that were also expected to influence race performance, we asked for the training status and the individual goal setting. Training status was assessed by asking participants how many weeks they had trained intensively for the race. Goal setting was assessed by two questions. First, participants were asked whether they just wanted to manage the distance ( $Y e s$ or $\mathrm{No}$ ). In addition, they were asked to write down a concrete time goal for the race.

Post-race questionnaire. The take-home booklet contained indicators of psychological and physiological crisis. The questions referred to four periods of the race: $10 \mathrm{~km}, 20 \mathrm{~km}, 30 \mathrm{~km}$, and $40 \mathrm{~km}$. Participants were instructed to imagine each period as vividly as possible and to answer the questions for each period, one after another. A description of prominent landmarks (i.e., sights, names of streets, crossing rivers) helped them to imagine the periods, and they were asked to give an answer that referred to the special period that was actually requested.

Indicators of psychological crisis. Indicators of psychological crisis were measured by asking directly for disengagement impulse and by asking 
questions to assess the costs of running farther and the benefits of disengaging from the race. Disengagement impulse was measured by the following two items: "To what extent did you experience the impulse to give up your race?" and "How often did you think 'Now I have to give up"?" Responses were provided on a 7-point scale ranging from 1 (not at all) to 7 (very much). The items were highly correlated for each time period (on average, $r=.73$, all $p s<.001)$. Thoughts about the costs of running farther and the benefits of disengagement were explained by examples (i.e., "When I run further, exhaustion will become unbearable," and "When I stop running, I could rest and relax," respectively) and were assessed by asking participants the following questions: "How often in the race period around Kilometer 10 (and 20, 30 , and 40, respectively) did you think about costs of running further?" and "How often in the race period around Kilometer 10 (and 20, 30, and 40, respectively) did you think about benefits of not running further?" Participants rated both items on a 7-point scale ranging from 1 (never) to 7 (very often).

Correlations between costs and benefits were high (on average, $r=.75$, all $p s<.001$ ). A score of psychological crisis for each time period was created by averaging the highly correlated items of disengagement impulse and thoughts about benefits and costs (on average, $r=.70$, all $p \mathrm{~s}<.001$ ). Cronbach's alpha for this scale varied between .66 (Kilometer 10) and .93 (Kilometer 20).

Indicators of physiological crisis. Indicators of physiological crisis were measured by asking participants to rate the intensity of 16 physiological symptoms on a 5-point scale ranging from 1 (not at all) to 5 (high intensity). Items were symptoms that typically occur during a marathon race, such as physical exhaustion, muscle pain, dizziness, back pain, and feet blisters. The scale was reliable, with internal consistencies ranging between .72 (Kilometer 10) and .86 (Kilometer 30).

Race performance. Race performance was measured objectively by the marathon organizers with a usual time registration procedure. A chip that was attached to each runner's shoe gave a signal when crossing the starting and finishing lines, and the running time could be calculated. We asked runners to allow us to use their start numbers to look up their running times that were published after the race on the website of the marathon organizers. Note that higher values in running times indicate poorer race performance.

\section{Results}

Participant Attrition and Preliminary Analyses

We checked whether participants who quit their participation after completing the first questionnaire differed from participants who completed both 
questionnaires. Participants who decided to drop out of the study had a higher training status than did participants completing the study (dropped out, $M=28.8, S D=14.1$; completed, $M=19.1, S D=14.1), t(127)=2.00$, $p<.05$; but did not differ in terms of goal setting, $t(106)=0.17, p>.80$. There were also no differences between participants who failed to write down their start numbers and those who did not: training status, $t(118)=1.36, p>.17$; goal setting, $t(102)=0.15, p>.80$; psychological crisis, $t(118)=1.42, p>.15$; and physiological crisis, $t(118)=0.32, p>.70$. Further analyses reveal that neither age nor gender of the runners significantly influenced the results.

\section{Existence of a Psychological Crisis}

Figure 1 illustrates that indicators of psychological crisis and physiological crisis varied during the race. To test whether variation was significant, ANOVAs with the repeated-measures factor of Race Period $(10 \mathrm{~km}, 20 \mathrm{~km}$, $30 \mathrm{~km}$, or $40 \mathrm{~km}$ ) were conducted for psychological and physiological crisis, respectively. Both analyses reveal significant within-subjects effects, $F(3$, $357)=42.66, p<.001$; and $F(3,357)=246.59, p<.001$, for psychological and physiological crises, respectively. This indicates significant variation during the race.

Additional pairwise comparisons adjusted for multiple comparisons (Bonferroni) confirm that all variations of indicators of psychological and

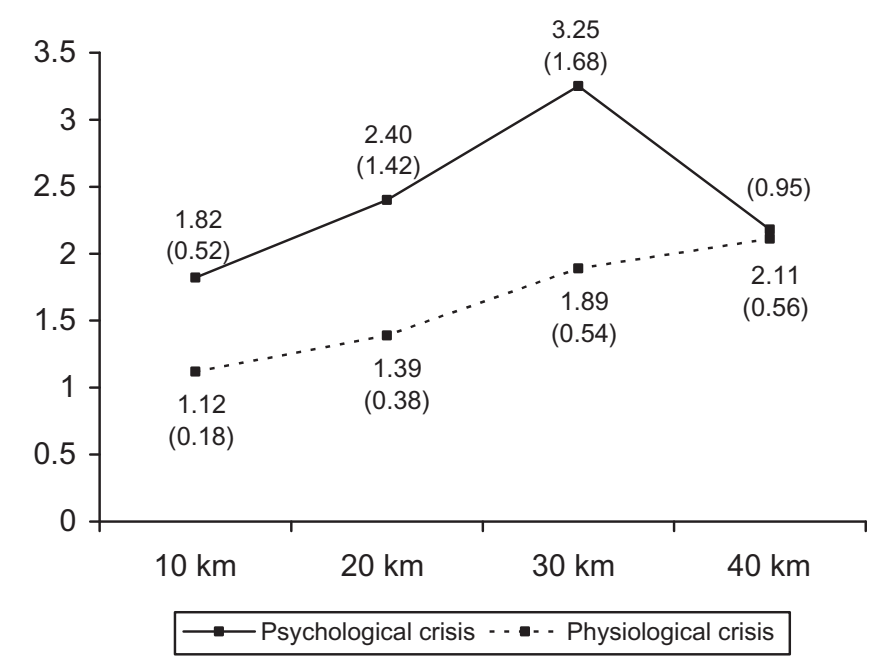

Figure 1. Means $(S D \mathrm{~s})$ of indicators of psychological and physiological crisis during the course of the race: Study 1. 
physiological crisis were significant (all $p \mathrm{~s}<.001$ ). To argue that indicators of psychological crisis peaked at Kilometer 30 , we first had to show that the increase of indicators from 20 to $30 \mathrm{~km}$ was higher than the increase of indicators from 10 to $20 \mathrm{~km}$. We analyzed differences between time periods on an individual level. The difference between 20 and $30 \mathrm{~km}$ was significantly higher than the difference between 10 and $20 \mathrm{~km}$ for indicators of a psychological crisis, $F(1,119)=1.37, p<.05$; as well as for indicators of a physiological crisis, $F(1,119)=18.49, p<.001$. A second result that confirms our hypothesis of a peak of psychological crisis at Kilometer 30 was the significant decrease of indicators after $30 \mathrm{~km}, t(119)=7.85, p<.001$. In contrast, indicators of physiological crisis increased further after Kilometer 30, $t(119)=7.47, p<.001$. Thus, indicators of a psychological crisis peaked at $30 \mathrm{~km}$, thereby marking a point of the strongest psychological crisis during a marathon race. Therefore, we decided to concentrate on psychological crisis at Kilometer 30 in subsequent analyses.

\section{Psychological Crisis and Race Performance}

Table 1 shows descriptive statistics and correlations of psychological crisis, physiological crisis, training status, goal setting, and running time. As expected, psychological crisis was positively correlated with running time $(r=.30, p<.01)$, indicating a lower race performance. Running time was also correlated with goal setting and training status $(r=.75, p<.001$; and $r=.42$, $p<.01$, respectively), indicating that these variables should be controlled in further analysis. Psychological and physiological crisis were highly correlated $(r=.61, p<.001)$.

Table 1

Descriptive Statistics and Correlations Among Variables: Study 1

\begin{tabular}{lrccccc}
\hline & \multicolumn{1}{c}{$M$} & \multicolumn{1}{c}{$S D$} & 1 & 2 & 3 & 4 \\
\hline 1. Psychological crisis & 3.25 & 1.68 & - & & & \\
2. Physiological crisis & 1.89 & 0.54 & $.61^{* * *}$ & - & & \\
3. Training status & 19.74 & 14.29 & $.20^{*}$ & $.21^{*}$ & - & \\
4. Goal setting & 234.24 & 27.01 & -.02 & .01 & $.21^{*}$ & - \\
5. Running time & 247.52 & 33.67 & $.30^{* *}$ & .13 & $.42^{* * *}$ & $.75^{* * *}$ \\
\hline
\end{tabular}

Note. $N=109$. Correlations with goal setting are based on 97 valid data sets. ${ }^{*} p<.05 .{ }^{* *} p<.01$. 
Table 2

Hierarchical Regression of Running Time: Study 1

\begin{tabular}{lcccc}
\hline & $\Delta R^{2}$ & $d f$ & $\Delta F$ & $b$ \\
\hline $\begin{array}{l}\text { Step 1: Control variables } \\
\quad \text { Training status }\end{array}$ & .60 & 2,94 & $69.88^{* * *}$ & \\
$\quad$ & & & $.15^{*}$ \\
$\quad$ Goal setting & & & & $.71^{* * *}$ \\
Step 2: Crises & .04 & 2,92 & 5.79 & \\
$\quad$ Psychological crisis & & & & $.28^{*}$ \\
$\quad$ Physiological crisis & & & & -.13 \\
Cumulative $R^{2}$ & .64 & 4,92 & $41.39^{* * *}$ & \\
\hline
\end{tabular}

Note. $N=97 . b=$ standardized regression coefficient in the regression equation. $* p<.05 . * * * p<.001$.

To find out whether psychological crisis accounted for variance that was independent of physiological crisis, we conducted a hierarchical regression analysis of running time using the following procedure (see Table 2). First, we entered the control variables of training status and goal setting into the regression analysis (Step 1), and then psychological and physiological crisis were entered simultaneously in Step 2. As can be seen in Table 2, after controlling for training status and goal setting, psychological crisis predicted running time over and beyond indicators of physiological crises $(b=5.22$, $\left.S E_{\mathrm{b}}=1.56, \Delta R^{2}=.045\right), t(92)=3.34, p<.01$. Runners who experienced a severe psychological crisis took longer to complete their race than did runners experiencing a less severe crisis.

\section{Discussion}

Study 1 examined the indicators of psychological crisis throughout the course of a marathon race and whether a psychological crisis predicted poor race performance. Knowing that an energy crisis (i.e., "the wall") is most likely to occur at about Kilometer 30, we expected the psychological crisis also to occur at this period. The results support our hypothesis, showing an increase of psychological and physiological crises from 10 to $20 \mathrm{~km}$, followed by a peak increase from 20 to $30 \mathrm{~km}$.

The period at about Kilometer 30 was characterized by a high impulse of disengagement, as well as intensive thinking about the costs of goal striving 
and the benefits of goal disengagement. After that period, the courses of psychological and physiological crises were different. Whereas the symptoms of the physiological crisis increased further, the psychological crisis decreased up to Kilometer 40. This was a first hint of a partial independence of both types of crises. Total dependence would predict a parallel course of physiological and psychological crises. Another indication of differential crises was provided by the finding that the psychological crisis was a predictor of poor race performance when the influence of physiological crisis was controlled. In summary, both the existence of a psychological crisis and its negative effects on race performance were supported by our data.

\section{Study 2: Buffering Effects of Self-Verbalizations}

Study 2 investigates whether the main results of Study $1-$ a peak of indicators for a psychological crisis at Kilometer 30 and its negative effect on race performance - could be replicated. A second goal is to examine whether self-verbalizations are an effective self-regulatory tool to overcome the negative effects of psychological crisis in goal striving.

We tested our hypotheses by conducting an experimental field study in which one group of marathon runners was instructed to use selfverbalizations during a race. Because this group was provided with a tool to use in difficult phases of goal striving, we hypothesize that negative effects of psychological crisis on race performance will be diminished. We expect another group that was not instructed to use self-verbalizations to show poorer performance. According to a barrier-dependent effect of intervention, the use of self-verbalizations should moderate the effect of psychological crisis on race performance and leave the effect of physiological crisis unaffected.

\section{Method}

\section{Participants and Procedure}

To recruit participants, we followed the same basic procedure as in Study 1. Non-professional marathon runners who were visiting a marathon exhibition in Zurich were asked to participate in a study entitled "Motivation and Feelings During a Marathon Race.” A total of 110 runners (19 women, 91 men) volunteered to participate and completed a first questionnaire directly on the exhibition ground.

Participants were randomly assigned to one of two conditions: an experimental condition in which participants received a questionnaire with self- 
verbalization instructions $(N=58)$ or a control condition in which participants received no instruction to use self-verbalizations $(N=52)$. Both groups provided their starting numbers and answered questions concerning training status and goal setting. They were asked to complete a second questionnaire at home directly after the race. The second questionnaire was an online survey, and access to it was explained in detail. There were 5 participants who anticipated problems with the online version of the questionnaire, and they were given a paper-and-pencil version. As in Study 1, the second questionnaire contained questions about indicators of psychological and physiological crises referring to certain time periods during the race $(10 \mathrm{~km}, 20 \mathrm{~km}, 30 \mathrm{~km}$, and $40 \mathrm{~km})$.

\section{Self-Verbalizations List}

Because self-verbalizations were the core construct of our experimental manipulation, the construction of the self-verbalization list is described in detail. In order to get a valid list of self-verbalizations, we conducted a pilot study with a two-step procedure that consists of collecting typical selfverbalizations from long-distance runners. The self-verbalizations were rated by experts to create a shorter version.

In order to collect the self-verbalizations, we sent a message via a mailing list to marathon runners in a university sports group. The message explained that some long-distance runners use self-verbalizations, that we wanted to know how many runners use self-verbalizations, and that we were interested in concrete examples. All nine of the long-distance runners who responded to our request reported using self-verbalizations. They sent us 49 examples, including self-encouragement (e.g., "I say to myself 'You can do it!"”; "Stay on. You are good."), anticipation of positive consequences (e.g., "I will feel wonderful when crossing the finishing line!"; "Think of feeling like a proud hero when I have managed the distance."), and self-calming (e.g., "Stay cool and think of nothing"; "Everything is okay. Just concentrate on breathing.").

To shorten the list of self-verbalizations, we asked five long-distance running experts (i.e., individuals who had run more than five marathons) to rate the typicality of each item according to their own or other people's experiences. The items were rated on a 7-point scale ranging from 1 (not typical) to 7 (very typical). We retained 18 items on the basis of representativeness and nonredundancy. Sample items from the final self-verbalizations list are "Stay on. Don't give up"; "Run your own rhythm"; "Stay calm and you will do it"; and "I will be proud of myself if I can do it." 


\section{Measures}

Pre-race questionnaire. The questionnaire prior to the race contains instructions regarding the experimental manipulation and measurement of control variables.

Experimental manipulation. To induce self-verbalizations, it seemed absolutely necessary for participants to understand what we meant by selfverbalizations. To this end, the questionnaire described the phenomenon in detail and proposed the self-verbalizations previously described.

Participants were asked to rate how familiar they felt with each selfverbalization, so that they really came in contact with the phenomenon. Then, we asked participants to write down a self-verbalization with which they were most familiar and which they wanted to use during their race. They were told that their personal self-verbalizations can be one of the examples from the list or any other self-verbalization. After that, participants were instructed to write down their self-verbalizations a second time on an instructional leaflet that was perforated and that could be ripped out of the questionnaire. It also functioned as a reminder to access the online survey. Participants were asked to take the leaflet home and to read their selfverbalizations a few times prior to the race so that they can be sure to remember it easily during the race.

Participants in the control condition did not receive a list of selfverbalizations. They received only a leaflet to take home that included the web address of the online survey.

Control variables. As in Study 1, training status was assessed by asking participants how many weeks they had trained intensively for the race. Goal setting was assessed by asking all participants to write down their time goals (i.e., "Please write down your time goal for this race").

Post-race questionnaire. As in Study 1, the second questionnaire contained questions referring to four periods of the race $(10 \mathrm{~km}, 20 \mathrm{~km}, 30 \mathrm{~km}$, and $40 \mathrm{~km}$ ). Participants were again instructed to imagine each period as vividly as possible. They were told that it is very important to give an answer that refers to the period that is actually requested. Typical landmarks of the specific period (i.e., crossing a river, passing particular sights) were provided to aid participants in their recollection.

Indicators of psychological crisis. Indicators of psychological crisis were assessed by administering the same four questions that were employed in Study 1 (two questions about impulse of disengagement, and one question each about the costs of running farther and the benefits of disengagement). Internal consistency of the index of psychological crisis was adequately high with Cronbach's alphas ranging between .74 (Kilometer 40) and .89 (Kilometer 30). 
Indicators of physiological crisis. As in Study 1, indicators of physiological crisis were measured by asking participants to rate the intensity of physiological symptoms. Again, the scale was reliable, with internal consistencies ranging between .84 (Kilometer 10) and .87 (Kilometer 30). To assess the use of self-verbalizations during the race, the self-verbalization group was asked to rate how often they used their self-verbalizations at approximately Kilometers 10, 20, 30, and 40, respectively. Responses were rated on a 5-point scale ranging from 1 (never) to 5 (very often). Control group participants were asked whether they had used any mental strategies. Responses were listed freely.

Race performance. Race performance was registered as in Study 1. Because we needed start numbers to access runners' times, we stressed the importance of this variable in the instructions.

\section{Results}

Participant Attrition and Preliminary Analyses

All 110 of the marathon runners who completed the first questionnaire also completed the second questionnaire. The number of valid data sets decreased to 105 because 5 participants failed to write down their correct start numbers. The excluded participants (only 4.8\%) did not differ from the other participants in training status, $t(108)=1.30, p>.19$; goal setting, $t(108)=0.18, p>.85$; psychological crisis, $t(108)=1.55, p>.19$; or physiological crisis, $t(108)=0.36, p>.72$. Further analyses reveal that the runners' gender had no significant impact on the results.

\section{Existence of a Psychological Crisis}

To replicate the results of Study 1, we used control group participants' data. They followed the same procedure of data collection as did participants in Study 1. The upper part of Table 3 shows that indicators of psychological and physiological crisis changed during the race. We again conducted an ANOVA with the repeated-measures factor of Race Period $(10 \mathrm{~km}, 20 \mathrm{~km}$, $30 \mathrm{~km}$, and $40 \mathrm{~km}$ ), which reveals significant within-subjects effects for psychological crisis, $F(3,153)=7.61, p<.001$; as well as a significant effect for physiological crisis, $F(3,153)=97.18, p<.001$, indicating significant variations during the race.

As in Study 1, additional pairwise comparisons confirm that variations were significant (all $p \mathrm{~s}<.01$ ). Again, differences between time periods for 
Table 3

Means of Psychological Crisis and Physiological Crisis and Use of SelfVerbalization During a Marathon Race: Study 2

\begin{tabular}{|c|c|c|c|c|c|c|c|c|}
\hline & \multicolumn{2}{|c|}{$10 \mathrm{~km}$} & \multicolumn{2}{|c|}{$20 \mathrm{~km}$} & \multicolumn{2}{|c|}{$30 \mathrm{~km}$} & \multicolumn{2}{|c|}{$40 \mathrm{~km}$} \\
\hline & $M$ & $S D$ & $M$ & $S D$ & $M$ & $S D$ & $M$ & $S D$ \\
\hline \multicolumn{9}{|l|}{ Control group } \\
\hline Psychological crisis & 1.15 & 0.50 & 1.23 & 0.42 & 1.61 & 1.02 & 1.45 & 0.86 \\
\hline Physiological crisis & 1.22 & 0.37 & 1.46 & 0.55 & 2.10 & 0.89 & 2.63 & 0.92 \\
\hline \multicolumn{9}{|l|}{ Self-verbalization } \\
\hline Psychological crisis & 1.10 & 0.36 & 1.21 & 0.61 & 1.49 & 0.83 & 1.31 & 0.51 \\
\hline Physiological crisis & 1.10 & 0.20 & 1.34 & 0.30 & 1.80 & 0.53 & 2.25 & 0.58 \\
\hline $\begin{array}{l}\text { Frequency of self- } \\
\text { verbalization use }\end{array}$ & 1.43 & 0.80 & 1.93 & 0.83 & 2.72 & 1.12 & 2.66 & 1.45 \\
\hline
\end{tabular}

Note. Control group, $N=50$; self-verbalization group, $N=55$.

${ }^{a}$ Only for self-verbalization group.

each participant were computed. The difference between 20 and $30 \mathrm{~km}$ tended to be higher than the differences between 10 and $20 \mathrm{~km}$ for psychological crisis, $F(1,51)=3.17, p<.10$. Again, after Kilometer 30, the course of indicators of psychological crisis changed direction, $t(51)=-1.64, p<.10$. For indicators of a physiological crisis, this difference was higher for 20 to $30 \mathrm{~km}$ than for 10 to $20 \mathrm{~km}, F(1,51)=13.03, p<.01$. After Kilometer 30, there was a further increase in physiological crisis that reached significance, $t(51)=7.98, p<.001$. Results were similar to the results in Study 1. A psychological crisis at about Kilometer 30 was identified, which was used as a race performance predictor in further analyses.

\section{Psychological Crisis and Performance}

As can be seen in the upper part of Table 4, the relationships between central variables were similar to correlations in Study 1. Among runners in the control group, psychological crisis was significantly correlated with running time $(r=.38, p<.01)$, whereas physiological crisis was not $(r=.10$, $n s$.). Again, psychological and physiological crises were highly correlated $(r=.47, p<.01)$ and running time correlated positively with goal setting 
Table 4

Descriptive Statistics and Correlations Among Variables: Study 2

\begin{tabular}{|c|c|c|c|c|c|c|c|}
\hline & $M$ & $S D$ & 1 & 2 & 3 & 4 & 5 \\
\hline \multicolumn{8}{|l|}{ Control group } \\
\hline 1. Psychological crisis & 1.61 & 1.02 & - & & & & \\
\hline 2. Physiological crisis & 2.10 & 0.89 & $.47 * * *$ & - & & & \\
\hline 3. Training status & 17.69 & 9.64 & .15 & $.26 \dagger$ & - & & \\
\hline 4. Goal setting & 225.79 & 23.03 & .25 & .17 & .18 & - & \\
\hline 5. Running time & 231.86 & 29.03 & $.38 * *$ & .10 & .11 & $.83 * * *$ & - \\
\hline \multicolumn{8}{|c|}{ Self-verbalization group } \\
\hline 1. Psychological crisis & 1.49 & 0.83 & - & & & & \\
\hline 2. Physiological crisis & 1.80 & 0.53 & $.23 \dagger$ & - & & & \\
\hline 3. Training status & 18.53 & 9.23 & .08 & .12 & - & & \\
\hline 4. Goal setting & 225.93 & 28.15 & .09 & .08 & $.36^{* *}$ & - & \\
\hline 5. Running time & 224.93 & 33.03 & -.11 & .22 & $.31 *$ & $.75^{* * *}$ & - \\
\hline $\begin{array}{l}\text { 6. Frequency of self- } \\
\text { verbalization use }\end{array}$ & 2.18 & 0.80 & -.06 & .24 & -.03 & -.02 & -.03 \\
\hline
\end{tabular}

Note. Control group, $N=50$; self-verbalization group, $N=55$.

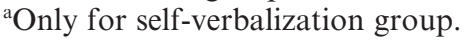

$\dagger p<.10 .{ }^{*} p<.05 .{ }^{* *} p<.01 .{ }^{* * *} p<.001$.

$(r=.83, p<.001)$. In contrast to Study 1 , training status was not significantly correlated with running time $(r=.11, n s$. $)$.

To test whether psychological crisis predicted poorer race performance independent of physiological crisis, a hierarchical regression analysis was conducted following the same procedure as in Study 1. Training status and goal setting were controlled in Step 1. In Step 2, psychological crisis and physiological crisis were entered simultaneously. Results show that in accordance with the results of Study 1, psychological crisis accounted for a significant amount of variance in running time over and above physiological crisis $\left(b=.18, S E_{\mathrm{b}}=.08, \Delta R^{2}=.72\right), t(47)=2.34, p<.05$.

\section{Buffering Effect of Self-Verbalizations}

To test whether the use of self-verbalizations buffers against the negative effect of psychological crisis on race performance, a hierarchical analysis of 
Table 5

Hierarchical Regression of Running Time on Psychological Crisis and Experimental Condition With Control Variables Held Constant: Study 2

\begin{tabular}{lcccc}
\hline & $\Delta R^{2}$ & $d f$ & $\Delta F$ & $b$ \\
\hline $\begin{array}{l}\text { Step 1: Control variables } \\
\quad \text { Training status }\end{array}$ & .60 & 2,102 & $76.01^{* * * *}$ & \\
$\quad$ & & & .02 \\
$\quad$ Goal setting & & & & $.75^{* * *}$ \\
$\begin{array}{l}\text { Step 2: First-order predictors } \\
\quad \text { Psychological crisis }\end{array}$ & .04 & 2,100 & 1.21 & \\
$\quad$ Experimental condition & & & & -.04 \\
$\quad \begin{array}{l}\text { Step 3: Psychological Crisis } \times \\
\quad \text { Experimental Condition }\end{array}$ & .02 & 1,99 & $5.16^{*}$ & $.16^{*}$ \\
\begin{tabular}{l} 
Cumulative $R^{2}$ \\
\hline
\end{tabular} & .63 & 5,99 & $33.34^{* * * *}$ & \\
\hline
\end{tabular}

Note. $b=$ standardized regression coefficient in the regression equation. $* p<.05 . * * * p<.001$.

regression was conducted (see Table 5). ${ }^{3}$ In Step 1, training status and goal setting were entered, followed by psychological crisis and the experimental condition in Step 2. The multiplicative interaction of psychological crisis and the experimental condition was entered in Step 3. The interaction of psychological crisis by experimental condition significantly predicted running time $\left(b=.17, S E_{\mathrm{b}}=.08, \Delta R^{2}=.02\right), t(99)=2.27, p<.05$. To interpret this interaction, we followed a procedure suggested by Cohen et al. (2003), in which values at 1 standard deviation above or below the mean of continuous predictor variables are entered in the regression equation.

Figure 2 illustrates the results for running times, which suggest that marathon runners with a large psychological crisis had lower running times (i.e., better race performance) when they used self-verbalizations than when they did not. To test whether differences between experimental groups were significant for runners with small crises and large crises, post hoc analyses, which employed a variant of the Johnson-Neyman technique (see Aiken \& West, 1991) were conducted. The results show that the difference between the self-verbalization group and the control group was significant for runners with large psychological crises, $t(99)=2.64, p<.01$; but not significant for runners with small psychological crises, $t(99)=-0.74, p=.46$.

${ }^{3}$ Continuous variables were centered before entering them into hierarchical regression analyses (Cohen, Cohen, West, \& Aiken, 2003). 


\section{Running time}

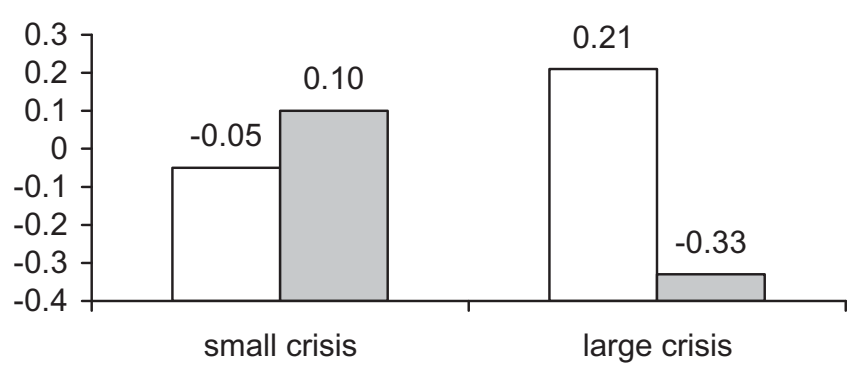

$\square$ Control $\square$ Self-verbalization

Figure 2. Running time ( $z$ values) as a function of psychological crisis and the use of selfverbalization: Study 2.

A second hierarchical regression with physiological crisis was conducted, similar to the regression approach reported previously. In Step 1, control variables were entered, followed by physiological crisis and experimental condition in Step 2. The Physiological Crisis $\times$ Experimental Condition interaction was entered in Step 3. In accordance with our assumptions, the interaction failed to reach significance $\left(b=-.13, S E_{\mathrm{b}}=.07, \Delta R^{2}=.01\right)$, $t(99)=-1.87, n s$.

\section{Supplemental Analyses}

In addition to the analysis that tested the hypothesized moderator effect of self-verbalizations, a further analysis was conducted to test whether using self-verbalizations influenced the course of psychological crisis directly. To this end, an ANOVA with the experimental condition as a between-subjects factor (i.e., self-verbalizations vs. control) and the repeated-measures factor of Course of Psychological Crisis (i.e., crisis at 10, 20, 30, and $40 \mathrm{~km}$, respectively) was conducted. The analysis reveals a main effect of course of psychological crisis, $F(1,108)=24.85, p<.001$; but no significant interaction effect, $F(1,108)=0.69$, $n s$, indicating that self-verbalizations did not influence the course of psychological crisis.

To check whether participants in the self-verbalization group made use of their self-verbalizations, we asked them how often they employed them in the different time periods. As can be seen in the last row of Table 3, the frequency 
of use of self-verbalization seems to parallel the course of psychological crisis. An ANOVA with the repeated-measures factor of Race Period (i.e., 10, 20 , 30 , and $40 \mathrm{~km}$ ) reveals a significant within-subjects effect, $F(3,172)=31.37$, $p<.001$, indicating that frequency of use of self-verbalization changed significantly. Participants in the control group, who were asked to report any strategy that they used in the time periods, wrote down things such as "I calculate minutes per kilometer" or "I run behind another runner who runs my speed and rhythm." Only a few marathon runners used self-verbalizations (i.e., "I said to myself, 'Keep on"”).

\section{Discussion}

The results of Study 2 confirm our hypotheses. First, the results of Study 1 could be replicated in showing the existence of a psychological crisis at about Kilometer 30 and its negative effects on race performance. Second, Study 2 successfully demonstrated the role of self-verbalizations as a selfregulatory tool.

A first indication that self-verbalizations are helpful to overcome difficult phases in goal striving can be seen in the parallel course of psychological crisis and the use of self-verbalization. Self-verbalizations were used mainly when runners experienced a high psychological crisis. Evidence for the effectiveness of self-verbalizations was provided by regression analyses, which reveal that self-verbalizations had a moderating effect on psychological crisis and on race performance. Marathon runners who experienced a low psychological crisis did not seem to take advantage of self-verbalizations as a selfregulatory tool. In contrast, among marathon runners who experienced a large psychological crisis and thus needed a self-regulatory tool, runners in the experimental group seemed to benefit from self-verbalizations, whereas control group participants performed on a lower level. Thus, when selfregulation was needed most, self-verbalizations served as an effective tool.

As hypothesized, self-verbalizations did not moderate the effect of physiological crisis on race performance. This supports our assumption of a barrier-dependent effectiveness of a psychological intervention strategy. Also in accordance with our hypothesis, the use of self-verbalizations moderated the effect of psychological crisis, but did not influence the extent of the psychological crisis directly.

\section{General Discussion}

The present research tested the effectiveness of a specific self-regulatory tool in a specific field of human goal striving. We used a marathon race to 
analyze the process of goal striving by arguing that it has a great deal in common with other goal striving processes, and we chose self-verbalizations as a self-regulatory tool.

It could be argued critically that a marathon is more associated with physiological processes than goals in other areas of goal striving. To support our assumption that a marathon is a good example of a goal-striving process, we had to show that the psychological components of the goal-striving process were partially independent of physiological components. The results support our assumptions, showing that psychological crisis accounted for variance that was independent of physiological crisis.

Another critical point for using a marathon as an example of goal striving refers to the sample. It could be argued intuitively that marathon runners are not representative of goal strivers in general because they have reached a high level in sport performance. Thus, they might have higher self-regulatory skills, higher achievement motives, or other characteristics that differentiate them from other people. Studies that have failed to identify dispositional characteristics of marathon runners (e.g., Ogles \& Masters, 2003) speak against this interpretation. Summing up the pros and cons, a marathon seems to be a good example to analyze a goal-striving process, including psychological crisis.

Overall, the results of Studies 1 and 2 are in line with our assumptions. Both studies consistently identified a psychological crisis at about Kilometer 30. Runners seem to struggle most with thoughts about giving up or quitting the race at about this distance, which experienced runners describe as "the wall." While indicators of a physiological crisis continue to increase, the psychological crisis decreases after this critical period of the race. In fact, at Kilometer 40, indicators of a psychological crisis are on the same level as at Kilometer 20.

The reduction of the psychological crisis may well be explained by the goal looms larger effect (cf. Förster, Higgins, \& Idson, 1998). A classic proposal of motivation research suggests that the motivation to pursue a goal increases as the distance from the goal decreases (Lewin, 1935; Miller 1944). Empirical evidence has generally supported this claim (e.g., Gjesme, 1974; Losco \& Epstein, 1977). Thus, the psychological crises of runners may be ameliorated at Kilometer 40 by the extra motivation of being close to the goal. The fact that goal distance did not affect indicators of a physiological crisis supports our claim that indicators of psychological and physiological crisis are partly independent of each other.

Both studies demonstrated that psychological crisis was a significant predictor of poor race performance. The pivotal question of our research was whether self-verbalizations buffer against the negative effect of psychological crisis on race performance. Our results show that they did. For marathon 
runners who experienced a large psychological crisis, the use of self-verbalizations minimized the negative effects of the crisis on race performance.

As expected, the use of self-verbalizations served as a moderator. Neither the psychological crisis itself nor the performance itself could be influenced directly by self-verbalizations, but the negative consequences of crisis on performance could be diminished. This suggests that self-verbalizations are a useful tool that can be applied when difficulties in goal striving occur. This is in accordance with analyses of adult use of self-verbalizations: Selfverbalizations are used in difficult situations in which they serve to analyze the task situation, to coordinate actions, to plan and organize, to evaluate actions, and to regulate emotions (e.g., Duncan, 1998; Duncan \& Cheyne, 1999; Vygotsky, 1934/1987). Without difficulties in goal striving, selfverbalizations are not needed, and using them makes no difference.

Our study provides clear evidence that self-verbalizations are an effective self-regulatory strategy in adult goal-striving processes. However, their effectiveness seems to depend on a precondition: Although every marathon runner in our pilot study was familiar with self-verbalizations, it seems as if they did not use them spontaneously. Analyses of strategies used by control participants show that only a few runners used self-verbalizations without being instructed to do so.

In contrast to studies demonstrating the natural use of self-verbalizations (e.g., Duncan \& Cheyne, 1999), our study suggests that participants had to be instructed to use self-verbalizations. Further research is needed to test what kind of instruction works best. Maybe it would help to form an implementation intention (Gollwitzer, 1993) that links the self-regulatory tool with the situation where it is mostly needed. Another research question is what kind of self-verbalization works best. Maybe it makes a difference whether selfverbalizations support regulation of emotion, support regulation of motivation, or support problem solving.

A methodological limitation of our research is that we measured the relevant data retrospectively. Although we asked the runners to experience the race periods as vividly as possible and described specific landmarks to help them recollect their experiences, it is nevertheless impossible to exclude the influence of retrospective biases. The only way to overcome this limitation is to conduct studies that measure data online; for example, with the experience sampling method (Cerin, 2004; Fave, Bassi, \& Massimini, 2003). However, most marathon runners would probably object to such a procedure, assuming that it may interfere with their concentration during the race.

In conclusion, self-verbalizations were shown to be an effective selfregulatory tool to deal with the psychological crisis of marathon runners. Further research is needed to test in detail how runners can best be instructed 
and whether the use of self-verbalizations can be transferred into other areas of human goal striving.

\section{References}

Aiken, L. S., \& West, S. G. (1991). Multiple regression: Testing and interpreting interactions. Newbury Park, CA: Sage.

Brandstätter, V. (2003). Persistenz und Zielablösung [Persistence and goal disengagement]. Göttingen, Germany: Hogrefe.

Burton, D. (1989). The impact of goal specificity and task complexity on basketball skill development. Sport Psychologist, 3, 34-47.

Burton, D. (1993). Goal setting in sport. In R. N. Singer, M. Murphey, \& L. K. Tennant (Eds.), Handbook of research on sport psychology (pp. 467-491). New York: Macmillan.

Burton, D., Naylor, S., \& Holliday, B. (2001). Goal setting in sport. In R. N. Singer, H. A. Hausenblas, \& C. M. Janelle (Eds.), Handbook of sport psychology (pp. 497-528). New York: John Wiley.

Carver, C. S., \& Scheier, M. F. (1990). Principles of self-regulation: Action and emotion. In E. T. Higgins \& R. M. Sorrentino (Eds.), Handbook of motivation and cognition (pp. 3-52). New York: Guilford.

Cerin, E. (2004). Predictors of competitive anxiety direction in male tae kwon do practitioners: A multilevel mixed idiographic/nomothetic interactional approach. Psychology of Sport and Exercise, 5, 497-516.

Cohen, P., Cohen, J., West, S. G., \& Aiken, L. S. (2003). Applied multiple regression/correlation analysis for the behavioral sciences ( $3^{\text {rd }}$ ed.). Hillsdale, NJ: Lawrence Erlbaum.

Duncan, R. M. (1998). Experimental studies of the forms and functions of private speech in adults. Unpublished doctoral dissertation, University of Waterloo, Waterloo, Ontario, Canada.

Duncan, R. M., \& Cheyne, J. A. (1999). Incidence and functions of selfreported private speech in young adults: A self-verbalization questionnaire. Canadian Journal of Behavioural Science, 31, 133-136.

Elliot, A. J., \& Church, M. A. (1997). A hierarchical model of approach and avoidance achievement motivation. Journal of Personality and Social Psychology, 72, 218-232.

Emmons, R. A. (1989). The personal striving approach to personality. In L. A. Pervin (Ed.), Goal concepts in personality and social psychology (pp. 87-126). Hillsdale: NJ: Lawrence Erlbaum.

Fave, A. D., Bassi, M., \& Massimini, F. (2003). Quality of experience and risk perception in high-altitude rock climbing. Journal of Applied Sport Psychology, 15, 82-98. 
Förster, J., Higgins, E. T., \& Idson, L. C. (1998). Approach and avoidance strength during goal attainment: Regulatory focus and the "goal looms larger" effect. Journal of Personality and Social Psychology, 75, 11151131.

Gjesme, T. (1974). Goal distance in time and its effects on the relations between achievement motives and performance. Journal of Research in Personality, 8, 161-171.

Gollwitzer, P. M. (1990). Action phases and mind sets. In E. T. Higgins \& R. M. Sorrentino (Eds.), Handbook of motivation and cognition: Foundations of social behavior (Vol. 2, pp. 53-92). New York: Guilford.

Gollwitzer, P. M. (1993). Goal achievement: The role of intentions. In W. Stroebe \& M. Hewstone (Eds.), European review of social psychology (Vol. 4, pp. 141-185). Chichester, UK: Wiley.

Grote, I., \& Baer, D. M. (2000). Teaching compliance with experimentally managed self-instruction can accomplish reversal shifts. Journal of Developmental and Physical Disabilities, 12, 217-233.

Hardy, J., Hall, C. R., \& Alexander, M. R. (2001). Exploring self-talk and affective states in sport. Journal of Sports Sciences, 19, 469-475.

Hardy, J., Hall, C. R., \& Hardy, L. (2004). A note on athletes' use of self-talk. Journal of Applied Sport Psychology, 16, 251-257.

Hartig, M., \& Kanfer, F. H. (1973). The role of self-instructions in children's resistance to temptations. Journal of Personality and Social Psychology, $25,259-267$.

Heckhausen, H., \& Gollwitzer, P. M. (1987). Thought contents and cognitive functioning in motivational versus volitional states of mind. Motivation and Emotion, 11, 101-120.

Hughes, C. (1992). Teaching self-instruction utilizing multiple exemplars to produce generalized problem-solving among individuals with severe mental retardation. American Journal of Mental Retardation, 97, 302-314.

Kanfer, F. H., Reinecker, H., \& Schmelzer, D. (2000). SelbstmanagementTherapie [Persistence and goal disengagement]. Berlin: Springer.

Kanfer, F. H. (1990). The scientist-practitioner connection: A bridge in need of constant attention. Professional Psychology: Research and Practice, 21, 264-270.

Kanfer, R., \& Kanfer, F. H. (1991). Goals and self-regulation: Applications of theory to work settings. In M. L. Maehr \& P. R. Pintrich (Eds.), Advances in motivation and achievement (Vol. 7, pp. 287-326). Greenwich, CT: JAI Press.

Klinger, E. (1996). The contents of thoughts: Interference as the downside of adaptive normal mechanism in thought flow (pp. 3-23). Mahwah, NJ: Lawrence Erlbaum.

Kronk, C. (1994). Private speech in adolescents. Adolescence, 29, 781-804. 
Kuhl, J. (1983). Motivation, Konflikt und Handlungskontrolle [Motivation, conflict, and action regulation]. Berlin: Springer.

Kuhl, J. (1984). Volitional aspects of achievement motivation and learned helplessness: Toward a comprehensive theory of action-control. In B. A. Maher (Ed.), Progress in experimental personality research (Vol. 13, pp. 99-171). New York: Academic Press.

Kuhl, J. (2000). The volitional basis of personality systems interaction theory: Applications in learning and treatment contexts. International Journal of Educational Research, 33, 665-703.

Lauth, G. W., \& Schlottke, P. F. (1997). Training mit aufmerksamkeitsgestörten Kindern. Diagnostik und Therapie [Training with children with attention disorders]. Weinheim, Germany: Beltz.

Lewin, K. (1935). A dynamic theory of personality. New York: McGraw-Hill.

Locke, E. A., \& Latham, G. P. (1985). Goal setting: A motivational technique that works! Englewood Cliffs, NJ: Prentice Hall.

Locke, E. A., \& Latham, G. P. (1990). A theory of goal setting and task performance. Englewood Cliffs, NJ: Prentice Hall.

Locke, E. A., Shaw, K. N., Saari, L. M., \& Latham, G. P. (1981). Goal setting and task performance: 1969-1980. Psychological Bulletin, 90, 125-152.

Losco, J., \& Epstein, S. (1977). Relative steepness of approach and avoidance gradients as a function of magnitude and valence of incentive. Journal of Abnormal Psychology, 86, 360-368.

Mahoney, M. J., \& Avener, M. (1977). Psychology of the elite athlete: An exploratory study. Cognitive Therapy and Research, 1, 135-141.

Meichenbaum, D. (1977a). Cognitive-behavior modification. An integrative approach. New York: Plenum.

Meichenbaum, D. (1977b). Methoden der Selbstinstruktion [The method of self-instruction]. In F. H. Kanfer \& A. P. Goldstein (Eds.), Möglichkeiten der Verhaltensänderung (pp. 407-450). München, Germany: Urban \& Schwarzenberg.

Meichenbaum, D., \& Goodman, J. (1971). Training impulsive children to talk to themselves: A means of developing self-control. Journal of Abnormal Psychology, 77, 115-126.

Meyers, A., Schleser, R., \& Okwumabua, T. (1982). A cognitive behavioral intervention for improving basketball performance. Research Quarterly for Exercise and Sport, 53, 344-347.

Miller, N. E. (1944). Experimental studies of conflict. In J. McV. Hunt (Ed.), Personality and the behavior disorders (Vol. 1, pp. 431-465). New York: Ronald Press.

Mischel, W., \& Patterson, C. J. (1976). Substantive and structural elements of effective plans for self-control. Journal of Personality and Social Psychology, 34, 942-950. 
Ogles, B. M., \& Masters, K. S. (2003). A typology of marathon runners based on cluster analysis of motivations. Journal of Sport Behavior, 26, 69-85.

Schack, T. (1996). Die Entwicklung von Handlungkontrollstrategien im Sportunterricht: Effektkontrolle in einer Zone der nächsten Entwicklung [The development of action control strategies in physical education: Effect evaluation]. In E. Witruk \& G. Friedrich (Eds.), Pädagogische Psychologie im Streit um eine neues Selbstverständnis (pp. 406-413). Landau, Germany: Empirische Pädagogik.

Siegrist, M. (1995). Inner speech as a cognitive process mediating selfconsciousness and inhibiting self-deception. Psychological Reports, 76, 259-265.

Tolman, E. E. (1932). Purposive behavior in animals and men. New York: Appleton-Century-Crofts.

Utter, A. C., Kang, J., Robertson, R. J., Nieman, D. C., Chaloupka, E. C., Suminski, R. R., et al. (2002). Effect of carbohydrate ingestion on ratings of perceived exertion during a marathon. Medicine and Science in Sports and Exercise, 34, 1779-1784.

Van Raalte, J. L., Cornelius, A. E., Brewer, B. W., \& Hatten, S. J. (2000). The antecedents and consequences of self-talk in competitive tennis. Journal of Sport and Exercise Psychology, 22, 245-256.

Vygotsky, L. S. (1987). Thinking and speech. In R. Rieber \& A. Carton (Eds.), The collected works of L. S. Vygotsky: Vol. 1. Problems of general psychology (pp. 39-285). New York: Plenum. (Original work published 1934)

Weinberg, R. S. (1994). Goal setting and performance in sport and exercise settings: A synthesis and critique. Medicine and Science in Sports and Exercise, 26, 469-477.

Weinberg, R. S. (2002). Goal setting in sport and exercise: Research to practice. In J. Van Raalte \& B. Brewer (Eds.), Exploring sport and exercise psychology (pp. 25-48). Washington, DC: American Psychological Association.

Whelan, J. P., Mahoney, M. J., \& Meyers, A. W. (1991). Performance enhancement in sport: A cognitive behavioral domain. Behavior Therapy, $22,307-327$

Ziemainz, H., \& Stoll, O. (1999). Stress und Stressbewältigung [Stress and coping with stress]. In D. Alfermann \& O. Stoll (Eds.), Motivation und Volition im Sport. Vom Planen zum Handeln. Köln, Germany: Bps-Verlag. 